\title{
Intrinsic Motivation in Saudi Learners of English as a Foreign Language ${ }^{\#}$
}

\author{
Christo Moskovsky* and Fakieh Alrabai
}

The University of Newcastle, NSW, Australia

\begin{abstract}
The paper presents an experimental study designed to measure levels of intrinsic motivation in learners of English as a Foreign Language in Saudi Arabia. As part of the study, a 27-item structured survey was administered to a randomly selected sample of 55 Saudi learners from public schools and universities. Data collected through the survey were subjected to some basic statistical analyses, such as "mean" and "standard deviation". Based on the results from the analysis, a number of generalizations and conclusions are made in relation to the role of motivation in the attainment of English as a foreign language in the Saudi educational setting. In addition, some recommendations are offered, which may enable Saudi teachers and learners of English as a foreign language to achieve better learning outcomes in an area widely associated by Saudis with lack of success.
\end{abstract}

\section{INTRODUCTION}

The importance of motivation as a factor in learning generally cannot be underestimated. In second language acquisition literature, the big role that motivation plays in the attainment of non-primary languages is practically unanimously acknowledged. It is, therefore, hardly surprising that over the past 30 or 40 years there have been numerous studies investigating various aspects of the issue of motivation within the field of teaching/learning second/foreign languages. Many of these studies gave rise to proposals in relation to what motivation as a concept and a theoretical construct involves, as well as in relation to practical (e.g. classroom) dimensions of the issue. It is notable that historically the focus of attention has been predominantly on the integrative/instrumental motivation dichotomy originally proposed by Gardner and Lambert [1], and it has only been more recently that researchers have started looking at other aspects and types of motivation in relation to second/foreign language learning, such as intrinsic motivation (see e.g. [2] and [3]).

In literature there are different conceptualizations of intrinsic motivation. According to some scholars [4, 5] intrinsic motivation involves enhancing people's self-concept by engaging them in activities that motivate them. Other theorists [6], however, have defined intrinsic motivation in a broader and simpler way: in terms of what people will do without external inducement. Intrinsic motivation has also been defined as "motivation to engage in an activity for its own sake" [7]. These definitions are not in contradiction with one another, but rather complement each other in articulating what intrinsic motivation is about. In relation to this, it is important to note that the concept of intrinsic motivation, especially when defined in a broader sense, is not in opposition to integrative or instrumental or any other type of motivation (except, of course, extrinsic motivation), as any one of

*Address correspondence to this author at the University of Newcastle, NSW, Australia; E-mail: Christo.Moskovsky@newcastle.edu.au

${ }^{\#}$ We would like to extend our thanks to Dr. Silvia Ratcheva for her insightful comments on an earlier version of the paper. them can be determined, to one extent or another, intrinsically (or extrinsically).

Lepper and Hodell [3] proposed four main factors as the principal sources of intrinsic motivation: CHALLENGE, CURIOSITY, CONTROL and FANTASY. The authors suggest that teachers should be aware of these factors and use them to enhance students' intrinsic motivation.

Vockell [8] accepts the validity of the four basic factors proposed by Lepper and Hodell, but claims that these only operate at the level of the individual, reflecting the individual's cognitive and personality characteristics. Vockell argues that in addition to these there are also interpersonal factors at play which, according to him, are: COMPETITION, COOPERATION and RECOGNITION. These are said to operate at the level of the group stimulating learners to engage in activities that would ultimately lead to higher achievement in learning.

In view of the fact that most of the questionnaire items used for the current study have been designed to capture the operation of several of these factors, a brief review of their conceptualization would be in order. Among the 'individual' factors, according to Vockell, CHALLENGE is based on the assumption that learners are likely to be intrinsically motivated by difficult tasks when: (a) they themselves set and try to achieve clearly defined objectives, (b) these objectives are not perceived as either extremely hard or as extremely easy, (c) learners are provided with constructive and encouraging feedback about their progress, and (d) learners feel confident and competent after completing these tasks.

Vockell also indicates that CURIOSITY involves the assumption that learners would be more motivated if they are provided with a more interesting and stimulating sensory and cognitive environment.

The individual factor CONTROL refers to the learners' level of control over what they do and how they do it. According to Vockell, learners will get a stronger sense of being in control if they recognize their learning activities to be relevant to what they are trying to accomplish, and if they feel that these activities have freely been chosen by them 
rather than having been imposed by someone else, e.g. the teacher.

FANTASY refers to the learners' ability to use their imagination to visualize make-believe events/situations which are related to the information being learned and at the same time satisfy learners' emotional needs [8].

Raffini [9] has identified ENJOYMENT as another relevant factor, arguing that students need to experience enjoyment in the learning process in order to feel intrinsically motivated. The same author discusses the interpersonal factor COMPETENCE and assumes that in order to increase the intrinsic motivation of students it is important to create an environment in which students can discover that their serious effort toward learning enables them to attain a sense of academic competence. The author further suggests that despite the fact that the amount of time and effort required for academic achievement varies considerably among students, they all need to experience the feeling of competence that comes from achievement.

Clément et al. [10] have indicated that COOPERATIVENESS, as well as group cohesion, may contribute to learner motivation. Schmuck and Schmuck [11] have found that young learners' academic achievements were enhanced when children were willing to help and support one another, and when friendship within the classroom was broadly dispersed among many peers.

Regarding the interpersonal factor RECOGNITION, Vockell [8] claims that learners feel satisfied when their accomplishments are recognized and appreciated by others. He states that recognition differs from competition in that it doesn't involve a comparison with the performance of other people.

As regards motivation within second/foreign language learning specifically, various studies have found relatively high levels of correlation between intrinsic motivation and second language achievement. Deci \& Ryan [2], for instance, have stated that intrinsic motivation improves the quality of learning. They have further suggested that results from various experimental studies indicate that intrinsic motivation may be closely related to what they call academic motivation. According to Noels and associates [12] intrinsic motivation is linked to learners' greater interest in course material and higher academic performance. Results from other studies [13] indicate that intrinsic motivation may be particularly beneficial for a sustained long-term involvement in learning a second/foreign language. This seems to be in line with findings reported in Ramage [14] demonstrating that continuing students tend to be more motivated to learn language for language's sake, in other words, tend to be more intrinsically motivated, than those students who decide to discontinue language studies.

While this expanded breadth of inquiry into second language motivation has increased knowledge about this issue and has brought to light interesting new data, understanding of what motivation involves (especially intrinsic motivation) and how it can be tapped into to provide better learning outcomes remains incomplete. This is particularly true about the Saudi educational context, in relation to which we have only been able to find a very small number of studies/publications dealing with the role of motivation in Saudi learners of Eng- lish as a foreign language (EFL), and all of these seem to be concerned almost exclusively with the integrative/instrumental motivation distinction.

Al-Amr [15], for instance, acknowledges that there are a number of valid reasons why instrumental motivation would be much more relevant in the Saudi setting than integrative motivation, not least because the second language is being learned away from the target language speakers and their culture. Such a proposition is not incongruent with what other scholars (like Clément and Kruidenier [16]) have suggested about the correlation between the type of motivation, e.g. integrative/instrumental, and the context in which the learning of the target language takes place, e.g. second/foreign language context.

Al-Otaibi's study [17], which is the only quantitative study we are aware of dealing with motivation in Saudi EFL learners, has provided some noteworthy findings. The responses obtained through the administration of a structured questionnaire involve, on average, relatively high values for both instrumental and integrative motivation, and at the same time relatively low values on questions tapping into the subjects' desire to commit themselves to effort-intensive activities in order to improve their second language competence or to engage in active use of the target language (inside or outside of the classroom). While such results can be interpreted in a variety of ways, the view taken here is that the latter types of responses may be more indicative than the former of the subjects' genuine motivation for learning English. This issue will briefly be considered again later on in relation to some of the data obtained in the current study.

Some of the Saudi sources dealing with second language motivation seem to be more concerned with ways in which motivation levels in Saudi EFL learners can be enhanced. A 2005 publication by Dr. Rao [18], a professor at King Fahd University of Petroleum and Minerals in Saudi Arabia, has offered some ideas in this regard, including initiating work towards task-oriented assessment, encouraging development of online materials, etc.

The only publication that we are aware of that comes close to dealing with the issue of intrinsic motivation is AlHazemi's 2000 paper [19] in which the author has argued that learning English should arise from within the learners themselves: ideally learners will have a strong desire to attain a high level of competence in the target language, and will actively seek the strategies/techniques that will best suit them to accomplish their learning goals. Al-Hazemi, however, has not provided any ideas or suggestions in relation to how to deploy the learners' existing reserves of intrinsic motivation or enhance them further.

In light of the relative paucity of research studies dealing with second language motivation in the Saudi context, particularly intrinsic motivation, the need for more research in this area hardly needs to be emphasized. The current study therefore provides new data which may be able to offer interesting insights about the role of intrinsic motivation for EFL learning in Saudi Arabia, and possibly about motivation more generally. The findings from this study can be expected to contribute to educators' understanding of the issue of motivation in Saudi EFL learners, and may be used for improving existing language teaching curricula. 


\section{BASIC OBJECTIVES OF THE STUDY}

The principal objective of this study is to collect, via a structured questionnaire, data in relation to levels and types of motivation in a random sample of Saudi learners of English as a foreign language. In addition, collected data are subjected to a range of basic statistical analyses, such as 'mean' and 'standard deviation'. Results from the analysis are presented and discussed, and, on the basis of these, the paper offers some suggestions in relation to motivational levels in Saudi EFL learners and possible ways in which existing motivation can be better deployed in order to achieve better learning outcomes. The paper also makes suggestions with regard to what further research can accomplish in this field of study.

\section{RESEARCH PROTOCOL}

This was a quantitative study involving a structured survey administered to a group of 55 Saudi learners of English as a foreign language. Only volunteers who formally indicated their consent to participate were recruited. With underage participants, their parents' consent was also obtained. Selection of participants (including their gender) was completely random from both rural and urban areas of the country, and was designed to cover as widely as possible the secondary and tertiary sector of public education in Saudi Arabia. Subjects were recruited from one intermediate school, one technology institute, two secondary schools and two university colleges. Their ages ranged from 12 to 27 years, with an overall mean of 20.5 years, as shown in chart below:

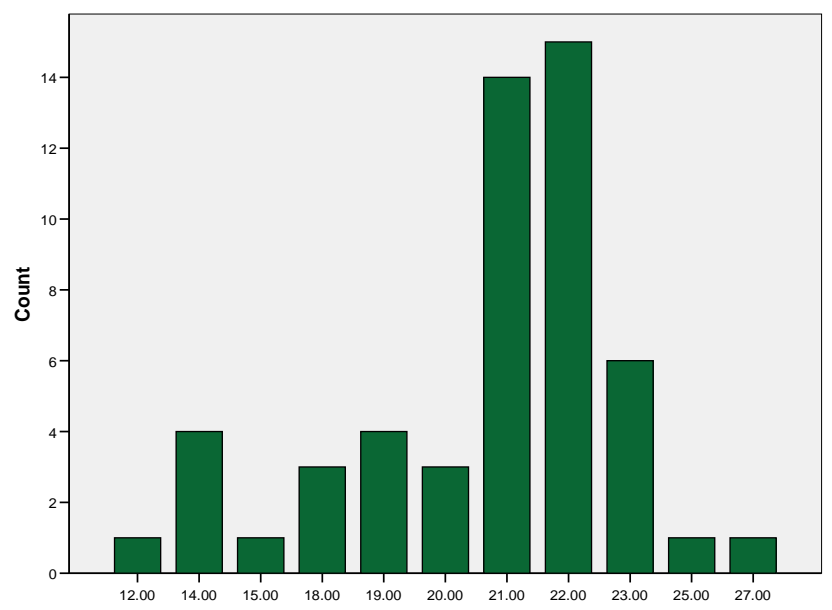

Chart 1. AGE.

In terms of gender, the participant group was relatively evenly divided, involving 29 males (52.73\%) and 26 females $(47.27 \%)$ (see the chart below):

Prior to the administration of the survey, participants were provided with comprehensive information about all aspects of the research project, including the nature of the research, the research methodology, the research objectives, etc. Participants were also provided with ample instructions about how to complete the questionnaire. 53 out of 55 participants $(96.37 \%)$ returned surveys with responses on all 27 items. The remaining two were incomplete, and have been excluded from the statistical analyses.

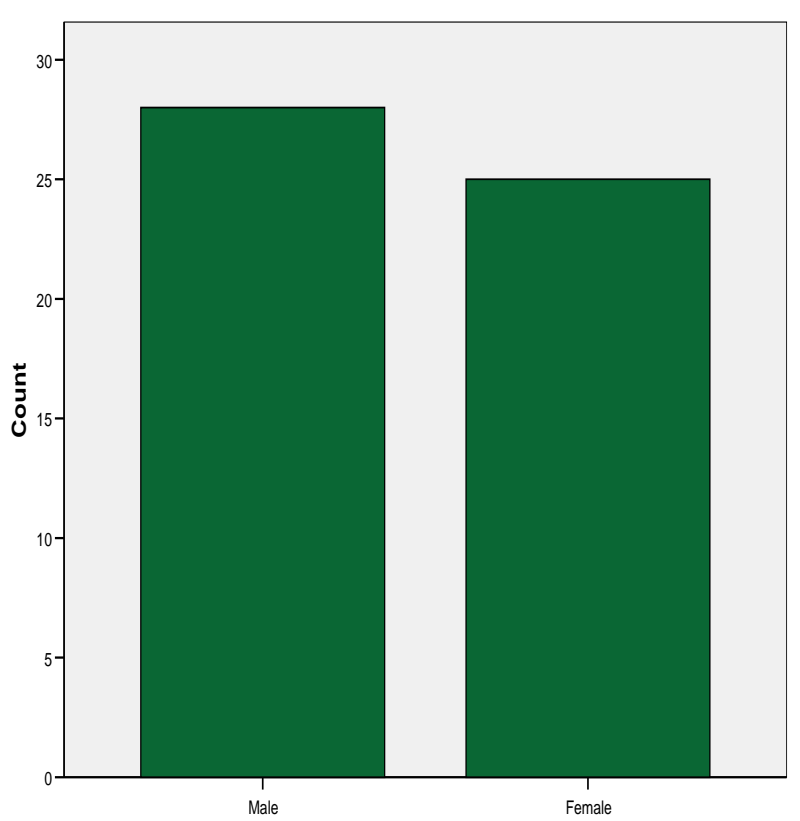

Chart 2. GENDER.

The questionnaire used for the purposes of the study was modeled on questionnaires, presented by Schmidt and Watanabe [20], with a distinct emphasis on intrinsic motivation and its possible sources, although questions targeting other types of motivation (integrative, instrumental and extrinsic) were also included. The complete sets of questions used in the survey are provided in Table $\mathbf{1}$ in the Appendix.

The questionnaire included 27 items designed to measure the four major types of motivation: intrinsic (items 1-20), extrinsic (item 26), integrative (items 23 and 24) and instrumental (items 21, 22, 25 and 27). In addition, questionnaire items targeting intrinsic motivation were also designed to identify the potential sources for this type of motivation, e.g. enjoyment (items 1-7), competitiveness (8, 9, 11, and 12), competence (item 10), curiosity about the English language and/or culture (items 13-14), control/autonomy over the learning process (item 15), challenge (items 16-19), and cooperativeness (item 20).

For each questionnaire item, participants had to select one of five possible options which were assigned numerical values ranging from (0) to (4) as follows:

STRONGLY DISAGREE $=1$

$\begin{array}{ll}\text { DISAGREE } & =2 \\ \text { DON'T KNOW } & =0 \\ \text { AGREE } & =3 \\ \text { STRONGLY AGREE } & =4\end{array}$

For obvious reasons, the three negatively worded questions 6, 7 and 19, however, were assigned the opposite set of values.

Data obtained through the administration of the questionnaire were subjected to a number of basic statistical analyses, such as 'mean' and 'standard deviation' using SPSS software. The 'mean' of hits to a particular questionnaire item was used to establish the relative level of a particular motiva- 
tional type: a higher mean presumably indicating a higher level of this type. Standard deviation was used to establish the relative disagreement in the responses provided for each questionnaire item. A summary of results is provided in Table 1. This table also involves a numerical value for the percentage of positive responses 'AGREE' and 'STRONGLY AGREE' for each of the questionnaire items. A comparative ranking of the questionnaire items according to percentage of positive responses is provided in Table $\mathbf{2}$ in the Appendix.

The data were further analyzed according to the gender and age variables. With regard to the latter, participants were divided into two groups: under 18 and over 18 years of age, the cut-off point being typically the age of transition from school to university.

In addition, repeated measures (ANOVA) were applied to the four major types of motivation: intrinsic, extrinsic, integrative and instrumental, in order to establish whether differences among them are statistically significant. T-tests were also conducted on the four basic types, as well as on individual items, to establish whether there are significant statistical differences in the responses according to the 'age' and 'gender' variables.

\section{DISCUSSION}

The data collected through the administration of the questionnaire contain a range of interesting aspects which deserve to be considered. Looking at the results from the statistical analyses (presented in the Appendix), the most striking aspect of the responses derived through the survey is their overwhelmingly positive nature. Table 2, e.g., shows that 22 out of 27 questions $(81.5 \%$ ) have yielded responses which involve $70 \%$ or more positive values, i.e. 'STRONGLY AGREE' and 'AGREE'. On the face of it, such results could be taken to indicate very high levels of motivation in Saudi EFL learners. Our view, however, is that such an interpretation of the results would be too simplistic, and is quite likely to be wrong. Assuming high levels of motivation in Saudi EFL learners would be in contradiction with their generally low level of second language achievement, and would not bring us any closer to understanding the roots of the problem of the relative lack of EFL success in Saudi Arabia.

However, if the positive responses provided by participants are not indicative of high motivation, how can they be explained? In our view, there are at least two valid reasons behind the highly positive responses. In the first place, in the field of psychology it has long been recognized that most people seem to be more inclined to respond positively, rather than negatively, to survey items, which may in part be reflective of a fairly strong inherent desire in people to get approval. In the second place, while positive responses may not necessarily be an indication of high situational or taskoriented motivation, they are nevertheless likely to reflect an essentially positive attitude to, and global motivation for, language learning more generally, and English as a foreign language more specifically. We briefly return to this point later on. In addition to this, most of the statements used as questionnaire items seem to be so reasonable and constructive, and seem to involve so much common sense that it may be very hard to respond to these in a negative fashion. Consider item \#16, for instance: "I know that studying English is not an easy task, but I am certain that if I worked hard, I would learn better". This statement has been given nearly 95\% of approval and comes third highest in the approval ranking in Table $\mathbf{2}$. Very few reasonable people would disagree with such a statement, regardless of what their actual motivation for learning a second/foreign language is. In this sense, item \#16 may not be the most effective instrument for measuring levels of second language motivation. Without going into a lot of unnecessary detail, it is likely that, to one extent or another, the same holds true for some of the other questionnaire items.

This line of reasoning receives some support from the analysis of responses to items on the lower end of the ranking table. Curiously enough, at the bottom of the table we find a relatively sharp drop in the approval percentage in what is otherwise a fairly gradual continuum of values. There is a drop of 15 points between the third and the second lowest, and then another drop of 6 points or so for the lowest ranked item \#3: "When English class ends, I often wish that we could continue". It is notable that item \#19, the second lowest, is one of the 'negative' items: "I prefer to sit and listen, and don't like being forced to speak in English classes.", and its score indicates that only $41.5 \%$ agree with the statement. In other words, around $60 \%$ of the respondents would agree with an opposing positive statement. This would suggest that the actual positive percentage for item \#19 would be around the 60 mark, ranking it in fifth lowest position above \#10 and \#24. Such a re-analysis of \#19 would leave item \#3, at $35.8 \%$, a whole 20 percentage points below the next one in the ranking, item \#24, at $56.6 \%$. We believe that it is significant that no difference of that magnitude can be found between any two other items in the ranking table.

The score of $35.8 \%$ for item \#3 is strikingly low given the otherwise very high approval rate (over $80 \%$ of the questionnaire items were rated above $70 \% ; 60 \%$ of the questionnaire items received approval of $80 \%$ and more), and therefore merits some attention. While it may not be possible to provide a definitive explanation for its lower approval without a postmortem interview with all of the participants, we take the view that the most likely explanation is that responding positively to \#3 would come at a "high cost" for the responder: it would involve a distinct commitment and even require a personal "sacrifice" on the part of the responder. This would be in contrast with most other questionnaire items which can be given positive responses at no "high cost". If this assumption is correct then one obvious inference would be that item \#3 is much more indicative of the respondents' second language motivation than most other items. Motivated learners are prepared to pay a high cost and even make sacrifices in order to achieve their goals. This finding seems to be in accordance with findings reported in the Al-Otaibi 2004 study [17].

To the extent that the analysis of the data derived through the survey can yield insights about motivation in Saudi EFL learners, it would appear that our results generally support the view that the 'instrumental motivation' type plays a more prominent role in foreign language contexts than the 'integrative' type, which seems more relevant to second language contexts. Items targeting instrumental motivation in our sample have received relatively high approval values, including item \#22: "I am learning English in order to be able to communicate with other people when I travel abroad" which 
was the only item to receive $100 \%$ positive responses. On the other hand, items \#23 "I am learning English because I am interested in the English language and the English culture" and \#24 "I am learning English because I would like to go and live in America, Australia, Britain or another English-speaking country", which were designed to measure levels of integrative motivation, have received, on a comparative basis, much lower scores $(73.6 \%$ and $58.5 \%$, respectively).

The chart below displays a comparative ranking of the four main types of motivation.

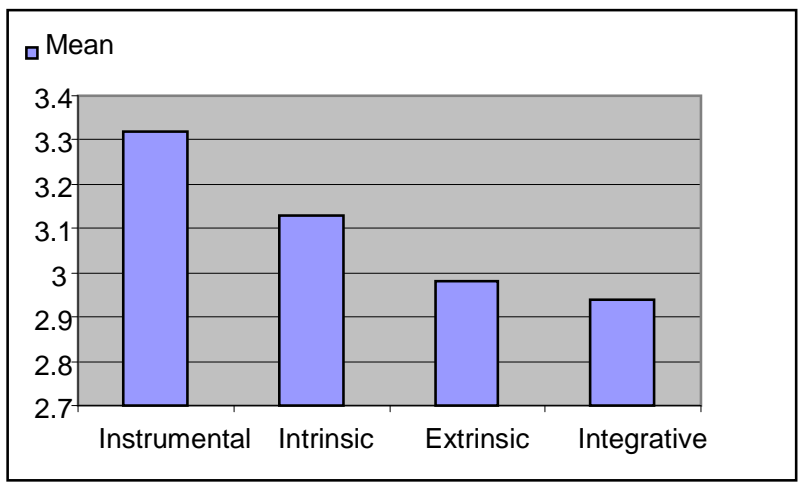

Chart 3. Comparative ranking of the four main types.

It is noteworthy, however, that the distinct numerical differences in the ranking of the four types are not of statistical significance, as demonstrated in the repeated measures (ANOVA) which we applied to the data. T-tests conducted on the four types also revealed no statistically significant differences (all $p \mathrm{~s}>.05$ ) according to gender and age.

Given that the focus of the study is on intrinsic motivation, it is interesting to see how responses on that type compare with responses on other types. The Chart below shows the means for all intrinsic motivation items as a group, compared with all other items, again taken as a group.

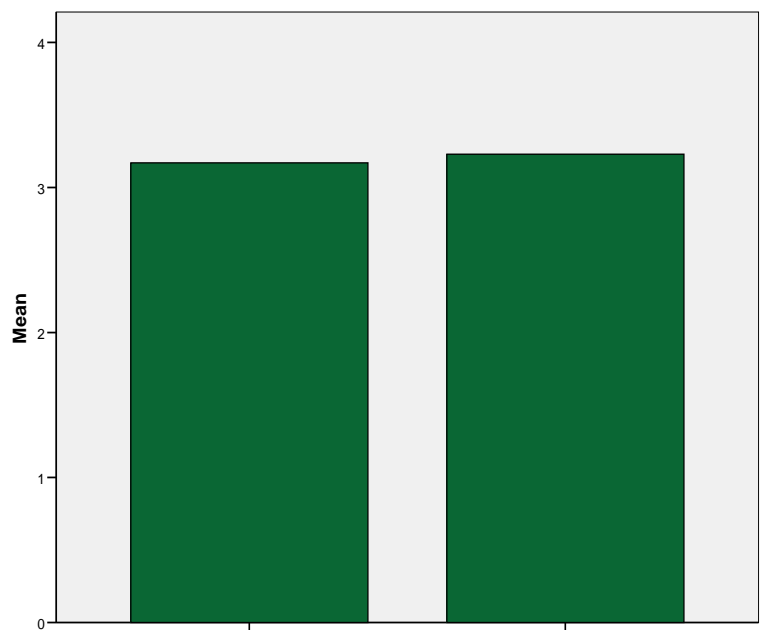

Chart 4. Intrinsic items vs. other items.

Obviously there are no significant differences between the two groups according to 'mean'. It is interesting to note that the items targeting intrinsic motivation are quite evenly spread over the whole of the ranking table (see Table $\mathbf{2}$ in the Appendix), which would actually be in line with one of the basic assumptions made in this paper, viz. that intrinsic motivation is a more general and encompassing type including other types like 'instrumental' and 'integrative'. It is therefore not surprising that we find intrinsic motivation items like \#7 and \#16 among the highest ranked items, and at the same time we find items like \#15 considerably lower in the ranking table. These results indicate that it may not be appropriate to treat intrinsic motivation as a single united type, but rather as a group of different types all relating to a drive coming from within the individual. They also show that some intrinsic motivation types may be more relevant to Saudi EFL learners than others.

One of the potentially significant findings of the study is in relation to gender-based differences in the type of preferred motivation. Male participants' most favored item was \#22: "I am learning English in order to be able to communicate with other people when I travel abroad", with a mean of 3.37. Female participants favored items \#13 "The pictures, drawings and cards in the English books attract me to learn English" (mean: 3.32 ), and \#14 "I have a great desire to learn the English language as a kind of fulfilling my curiosity" (mean: 3.76), both dealing with CURIOSITY. It is in relation to latter two items that the t-test reveals a statistically significant difference between the two genders: $t=-2.04, p<.05$ for $\# 13$, and $t=-2.533, p<.05$ for \#14.

It is also interesting to note that, as a whole, females seem to be slightly more motivated second language learners than males, which is not inconsistent with results reported in other studies. The difference, however, is not statistically significant $(p>.05)$.

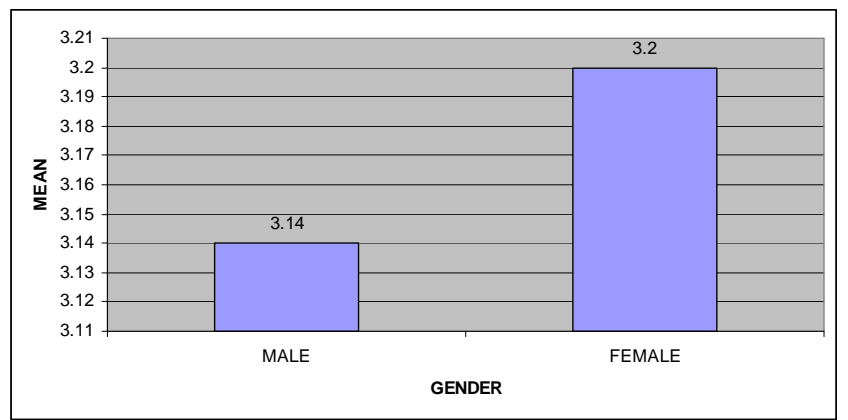

Chart 5. Comparative ranking according to GENDER.

With regard to the age factor, the analysis produced an almost identical mean for the two age groups: 3.1728 for the over 18-year-olds and 3.1675 for the younger group. Not surprisingly, the t-test yielded no statistically significant difference between the two age groups $(p>.05)$.

One interesting, and potentially important, difference between the two groups that emerged from the analysis was for the preferred type of motivation: the older group gave the highest approval rating to item \#22: "I am learning English in order to be able to communicate with other people when I travel abroad", while the younger group favored items \#13 "The pictures, drawings and cards in the English books attract me to learn English", and \#14 "I have a great desire to learn the English language as a kind of fulfilling my curios- 
ity". This strikes a curious coincidence with the findings about gender-based differences (see above). In relation to this, it is noteworthy that the analysis found no correlation between the gender and the age of the participants (e.g., we did not find that the older group consisted predominantly of males).

\section{CONCLUSIONS, IMPLICATIONS, RECOMMENDA- TIONS}

One of the great assets of the study reported here is the random selection of the sample of participants, which would allow us to make generalizations over the whole population of Saudi learners of English as a foreign language.

While, as suggested above, the data derived through the administration of the survey may not yield clear outcomes in relation to second language motivation in this population, they are nevertheless valuable and interesting, and contain important implications both for second/foreign language teaching/learning in the Saudi context and for research on motivation.

For reasons outlined earlier, we have been reluctant to interpret the overwhelmingly positive responses provided overall by participants to the questionnaire items as indicative of genuine motivation, but these responses can be seen as revealing about the participants' attitudes towards learning English as a foreign language generally, as well as attitudes towards specific aspects of the teaching/learning process. The data seem to show an unequivocally positive attitude on the part of Saudis to EFL learning, which may not in itself be equated with motivation, but is undeniably a very important prerequisite for motivation. Therefore one really important message to language teachers and educators arising from this research is for the need to find effective ways to "translate" learners' positive attitudes into motivation. It falls upon research to provide teachers and educators with ideas about how this can be accomplished. This issue will briefly be addressed further down.

In addition to this, participants' responses to individual questionnaire items can be interpreted as indicative of how they feel about various aspects of the teaching/learning process, as well as their own involvement in that process.

Consider the following instrumental motivation items (percentage of positive responses is provided in brackets alongside each item):

21. I am learning English in order to be able to read fiction in the English language. (84.9\%).

22. I am learning English in order to be able to communicate with other people when I travel abroad. (100\%).

25. I am learning English because knowledge of English will enable me to get a highly paid job. (84.9\%).

27. I am learning English because it will enable me to watch English-speaking movies and programs on satellite TV. $(75.5 \%)$.

From responses to these items, it seems clear that respondents had a very distinct awareness of the range of advantages that knowledge of English as a foreign language bestows on individuals in all aspects of their personal and professional lives. Second language motivation would only be a small step away from this awareness.

Responses to items, such as \#\#8, 9 and 11:

8. Getting a good grade in English is more important for me than getting such a grade in other courses. $(86.8 \%)$.

9. I want to learn English because it is important to show my ability to others. (86.8\%).

11. I learn English best when I am competing with other students. $(86.8 \%)$.

indicate that learners are prepared to be competitive, and that being able to demonstrate their superior achievement can play an important role in the learning of the target language.

Results from the analysis also indicate that Saudi learners have a relatively high regard for learning activities which will actively involve them, as well as give them a high level of control and autonomy over what they are doing in and outside of the classroom:

15. I feel that I am encouraged to learn English when my teacher sometimes gives me the choice to decide on what to study in the classroom. (73.6\%).

18. I prefer English classes in which there are lots of activities that allow me to participate actively. (84.9\%).

It is also interesting to note that respondents indicated a strong preference for learning activities involving group or pair work, e.g.:

20. I like English learning activities in which students work together in pairs or small groups. (83.1\%).

Participants' responses leave little doubt that 'curiosity' about the target language and its culture is a major factor for Saudi learners, as evident from items like \#14:

14. I have a great desire to learn the English language as a kind of fulfilling my curiosity $(86.8 \%)$.

The results from the study further provide evidence that motivational orientation may involve some gender- and agebased differences, and we believe that language teaching professionals should be aware of this issue and find ways to tailor teaching/learning activities to accommodate such differences.

Based on what we know about EFL teaching practices in the Saudi context, both from personal experience and from anecdotal evidence, foreign language teaching remains a fairly teacher-centred process which rarely (if ever) involves activities promoting independent autonomous learning. There is good reason to believe that motivation levels, and ultimately learning outcomes, will significantly improve if teachers engage their learners in interesting and challenging learning activities which will enable learners to be more active and more independent, e.g. in terms of having more control over what they are doing. The analysis also indicates that learners would feel more comfortable with activities involving group and pair work, and that providing learners with a sense of competence and achievement may go a long way towards building up learners' motivation to learn the second language. Obviously, this will be hard to accomplish unless, as proposed by Lepper and Hodell [3], language teachers are 
familiar with the range of factors promoting motivation, and know how to use them to the learners' advantage.

In summary of the findings in relation to motivation, it can be concluded that while results from the current study may not necessarily be interpreted as demonstrating high levels of motivation in Saudi EFL learners, these results seem to indicate quite strongly that Saudis possess fairly substantial 'dormant' reserves of motivation which in more favorable conditions could be deployed to produce better learning outcomes.

With respect to further research on second language motivation, the current study offers some potentially significant findings and implications. As already acknowledged, due to the way most of the questionnaire items were formulated, the survey did not seem to yield data which are sufficiently revealing in relation to the actual levels of second language motivation of Saudi EFL learners. We therefore recommend that future studies of motivation involving a structured survey include a much larger number of questionnaire items like \#3 in our survey. These are items which ask participants to indicate their readiness to commit to effort- and timeintensive activities towards the attainment of the target language. In our view, responses to items like \#3 and others, such as "I am prepared to pay a private tutor in order to improve my competence in English", are much more indicative of the learners' actual motivation than less committing statements like "I enjoy learning English". Such a questionnaire should certainly include items targeting other intrinsic motivation variables identified in literature, e.g. 'selfdetermination' and 'fantasy'.

Obviously any research study will gain from having a variety of methods for collecting data, such as observation, qualitative interviews, surveys, questionnaires, diaries, etc. The results from the current study indicate that a postmortem interview with at least some of the participants to discuss their survey responses may be very valuable, and may provide researchers with data which may otherwise remain hidden.

One of the most significant findings of the research reported here is in relation to intrinsic motivation: intrinsic motivation is not, and should not be regarded as, a single unified concept/type. In our data, survey items targeting different intrinsic motivation types were treated differently by our participants. Future research can substantially contribute to our understanding of what intrinsic motivation is by investigating the relative importance of different intrinsic motivation types for learners of a particular cultural and ethnolinguistic background (e.g. Saudis). In relation to this, it would be very desirable to explore the role that the Internet plays as a motivating factor for the learning of English as a second/foreign language. Given the Internet's increasing prominence in all aspects of life globally (including language learning), ignoring it as a powerful motivational force would leave the picture incomplete.

It can hardly be denied that finding effective ways of increasing learners' levels of motivation can lead to very solid gains in the attainment of the target language. It is in relation to this that, in our view, research on motivation can make its most substantial contribution to second/foreign language teaching/learning practices. Such a research will be conceptually and methodologically quite hard to conduct, because it will first have to identify specific techniques for enhancing various types of motivation, and then experimentally evaluate their effectiveness on two or more groups of language learners. The potential benefits of such a study, however, are such that it will be worthy of the effort.

In conclusion, this paper has presented and discussed the data derived through the administration of a structured survey on a random sample of Saudi learners of English as a foreign language. The survey specifically targeted the level of second language motivation in these learners. The findings from the research indicate that this population of second language learners have highly positive attitudes to learning English as a foreign language, and that they may be in possession of substantial reserves of 'latent' motivation. From what we have presented here, it is quite clear that there is a tremendous scope for additional work on an issue of second/foreign language teaching/learning whose importance cannot be exaggerated.

\section{APPENDIX}

\section{Table 1. Descriptive Statistics}

\begin{tabular}{|c|c|c|c|c|}
\hline QUESTION & $\mathbf{N}$ & Mean & $\begin{array}{l}\text { Percentage of Positive } \\
\text { Responses }\end{array}$ & St. Dev. \\
\hline 1. I really enjoy learning English Language. INTRINSIC (enjoyment) & 53 & 3.38 & $88.7 \%$ & .686 \\
\hline 2. My English class is a challenge that I enjoy. INTRINSIC (enjoyment) & 53 & 3.08 & $75.4 \%$ & .937 \\
\hline $\begin{array}{l}\text { 3. When English class ends, I often wish that we could continue. INTRINSIC (en- } \\
\text { joyment) }\end{array}$ & 53 & 2.17 & $35.8 \%$ & 1.069 \\
\hline $\begin{array}{l}\text { 5. I would study English even if it were not required by my school or university. } \\
\text { INTRINSIC (enjoyment) }\end{array}$ & 53 & 3.40 & $88.7 \%$ & 1.062 \\
\hline 6. I don't like English language learning. INTRINSIC (enjoyment) & 53 & 3.75 & $94.3 \%$ & .677 \\
\hline
\end{tabular}




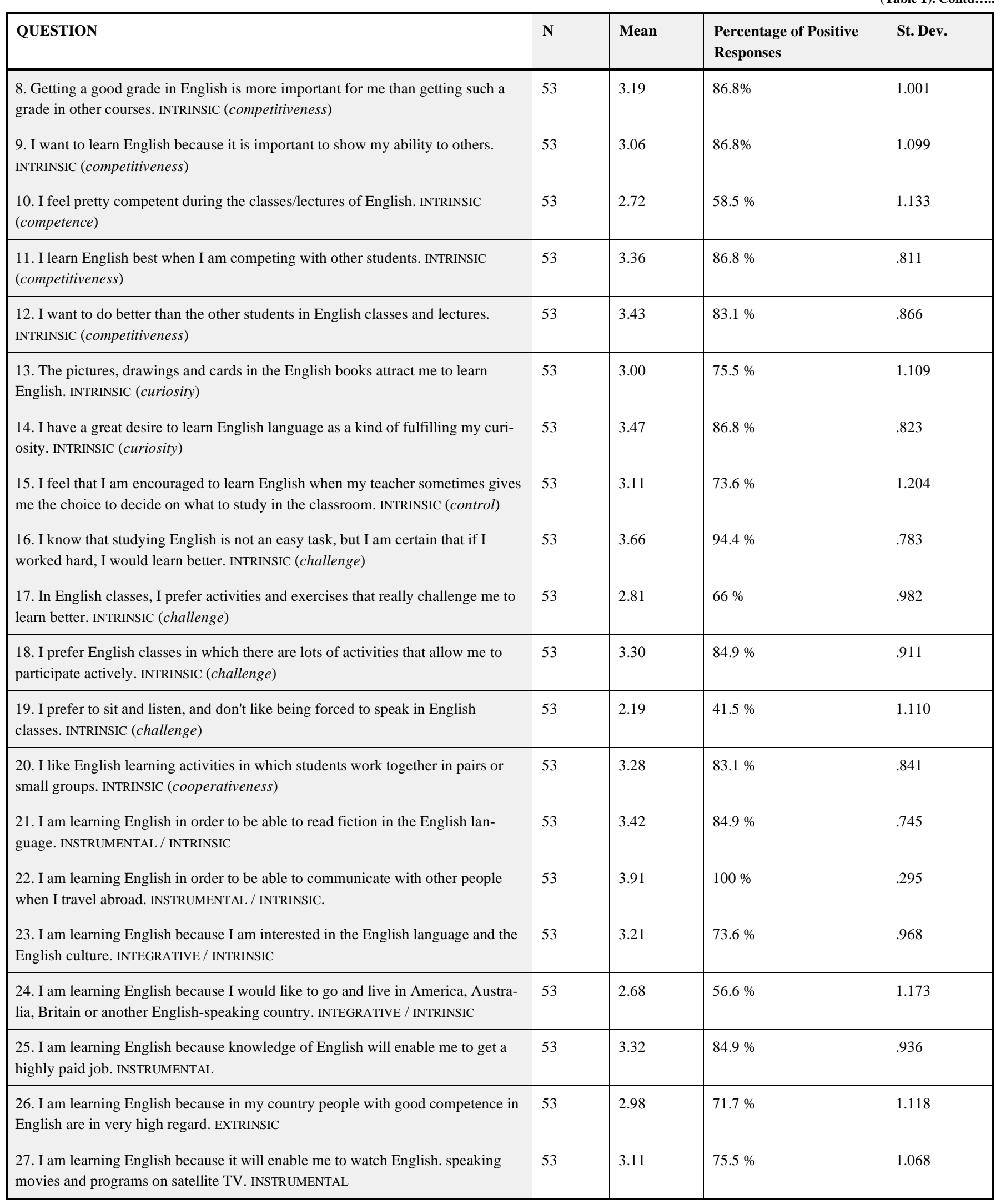


Table 2. Comparative Ranking

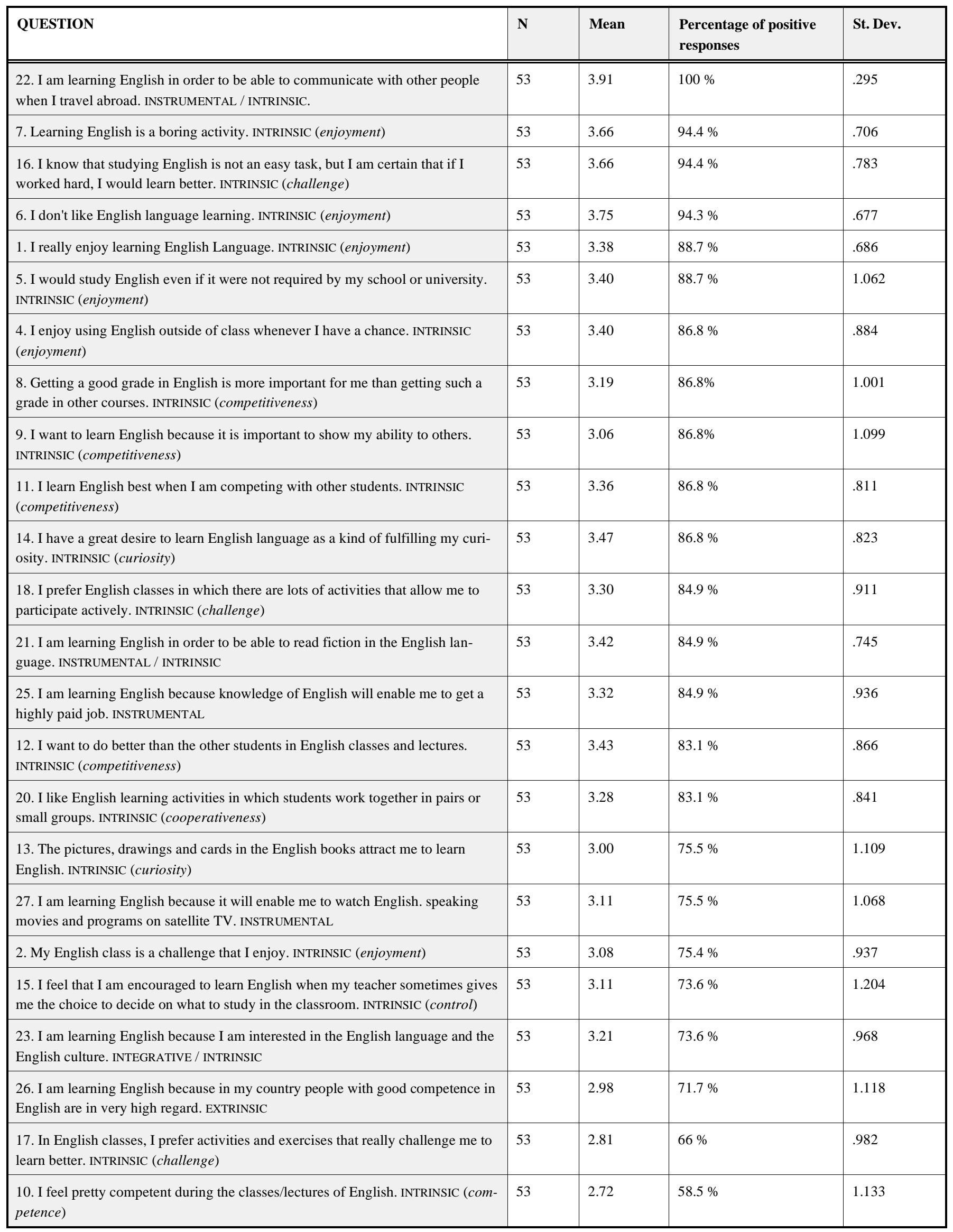


(Table 2). Contd.....

\begin{tabular}{|l|l|l|l|}
\hline QUESTION & N & Mean & $\begin{array}{l}\text { Percentage of positive } \\
\text { responses }\end{array}$ \\
\hline \hline $\begin{array}{l}\text { 24. I am learning English because I would like to go and live in America, Austra- } \\
\text { lia, Britain or another English-speaking country. INTEGRATIVE / INTRINSIC }\end{array}$ & 53 & 2.68 & $56.6 \%$ \\
\hline $\begin{array}{l}\text { 19. I prefer to sit and listen, and don't like being forced to speak in English } \\
\text { classes. INTRINSIC (challenge) }\end{array}$ & 53 & 2.19 & $41.5 \%$ \\
\hline $\begin{array}{l}\text { 3. When English class ends, I often wish that we could continue. INTRINSIC }(\text { en- } \\
\text { joyment })\end{array}$ & 53 & 2.17 & $35.8 \%$ \\
\hline
\end{tabular}

\section{REFERENCES}

[1] Gardner RC, Lambert WE. Attitudes and motivation in second language learning. Rowley, MA: Newbury House 1972.

[2] Deci EL, Ryan RM. Intrinsic motivation and self-determination in human behavior. New York: Plenum Press 1985.

[3] Lepper M, Hodell M. Intrinsic motivation in the classroom. In: Ames C, Ames R, Eds. Research on motivation in education: goals and cognitions. San Diego: Academic Press; 1989; pp. 73-105.

[4] Purkey WW, Schmidt JJ. The inviting relationship: an expanded perspective for professional counseling. Englewood, NJ: Prentice Hall 1987.

[5] Purkey WW, Stanley PH. Invitational teaching, learning and living. Washington, D.C.: National Education Association 1991.

[6] Malone T, Lepper M. Making learning fun: a taxonomy of intrinsic motivations for learning. In: Snow RE, Farr MJ, Eds. Aptitude, learning and instruction: conative and affective process analysis. Hillsdale, NJ: Lawrence Erlbaum 1987.

[7] Pintrich PR, Schunk DH. Motivation in education: theory, research, and applications. New Jersey: Prentice-Hall 1996.

[8] Vockell E. Educational psychology: a practical approach. [e-book] 2001 [cited 2006 Dec 04]; Available from: http://education. calumet.purdue.edu/vockell/EdPsyBook

[9] Raffini JP. 150 ways to increase intrinsic motivation in the classroom. Needham Heights, Massachusetts: Allyn and Bacon 1996.

[10] Clément R, Dörnyei Z, Noels KA. Motivation, self-confidence and group cohesion in the foreign language classroom. Lang Learn 1994; 44 (3): 417-48.

[11] Schmuck RA, Schmuck PA. A humanistic psychology of education: making the school everybody's house. Palo Alto, CA: National Press Books 1974.
[12] Noels KA, Clément R, Pelletier LG. Perceptions of teachers' communicative style and students' intrinsic and extrinsic motivation. Mod Lang J 1999; 83 (1): 23-34.

[13] Wang Y. The factors in L2 learning motivation and their pedagogical implications in English classroom. Sino-US Engl Teach 2006; 3 (7): $32-7$.

[14] Ramage K. Motivational factors and persistence in foreign language study. Lang Learn 1990; 40 (2): 189-219.

[15] Al-Amr B. Attitudes, motivation, and socio-cultural effects on English foreign language learning and proficiency: the Saudi Arabian context [MA thesis]. Essex: University of Essex 1998.

[16] Clément R, Kruidenier B. Orientations in second language acquisition: I. The effects of ethnicity, milieu and target language on their emergence. Lang Learn 1983; 33 (3): 273-91.

[17] Al-Otaibi G. Language learning strategy use among Saudi EFL students and its relationship to language proficiency level, gender and motivation [PhD Dissertation]. Indiana (PA): Indiana University of Pennsylvania 2004.

[18] Rao K. Faculty and student motivation: KFUPM faculty perspectives [serial online] 2005 [cited 2006 Dec 04]; Available from: http://www.kfupm.edu.sa/dad/richfiles/pdf/06krishnarao.pdf

[19] Al-Hazemi H. Lexical attrition of some Arabic speakers of English as a foreign language: a study of word loss. Internet TESL J [serial online] 2000 [cited 2006 Nov 26]; Available from: http://iteslj.org/Articles/Al-Hazemi-Attrition/

[20] Schmidt R, Watanabe Y. Motivation, strategy use, and pedagogical preferences in foreign language learning. In: Dörnyei Z, Schmidt R, Eds. Motivation and second language acquisition. Honolulu: University of Hawai'i: Second Language Teaching Curriculum Centre; 2001: 313-59.

(C) Moskovsky and Alrabai; Licensee Bentham Open.

This is an open access article licensed under the terms of the Creative Commons Attribution Non-Commercial License (http://creativecommons.org/licenses/by-nc/3.0/) which permits unrestricted, non-commercial use, distribution and reproduction in any medium, provided the work is properly cited. 